\title{
ASSESSMENT OF ANTI-INFLAMMATORY EFFECT OF GINGER ON MUCOSITIS INDUCED BY CETUXIMAB DRUG IN RATS
}

\author{
Wegdan Sayed Abd El Aziz Taha *, Mona Ezzat Wali ${ }^{* *}$ and Nermine Raouf Amin ${ }^{* * *}$
}

\begin{abstract}
Background: Oral mucositis induced by Cetuximab drug is associated with remarkable morbidity or permanent treatment discontinuation and therefore the use of ginger would be beneficial in treatment of mucositis. In this study we aimed to evaluate the effect of Ginger on the inflammatory reaction induced by Cetuximab drug through COX-2 immunoexpression in tongue mucosa of experimental rats.
\end{abstract}

Material and Methods: 16 rats and 16 archival blocks were used, divided into 4 groups: a control group ( 8 archival blocks), Cetuximab group ( 8 archival blocks), group III ( 8 rats received Ginger by oral gavage in parallel with Cetuximab) and group IV ( 8 rats received Ginger one week ahead of Cetuximab). Tongue dissection was performed at euthanization date. Area percent of the immunohistochemical expression of COX-2 was measured by software Leica Qwin 500.

Results: COX-2 was expressed in epithelium of Cetuximab group and loss of this expression was found in normal tongue mucosa and groups taking ginger. A statistically significant difference in COX-2 expression was present between Cetuximab group and groups taking ginger in parallel or one week ahead of Cetuximab.

Conclusion: Ginger administration can reduce inflammation caused by Cetuximab drug in tongue mucosa of rats.

KEYWORDS: Cetuximab, ginger, mucositis, COX-2.

\section{INTRODUCTION}

Cetuximab is a chimeric mAb binds with high affinity to the extracellular domain of the human EGFR, used in the treatment of squamous cell carcinoma. It induces mucositis in the form of moderate erythema and superficial ulcers associated with pain and difficulties in food intake (1). A wide array of agents has been used in management of oral mucositis induced by cancer therapy with significant concern regarding the use of nutraceuticals as they have fewer adverse effects ${ }^{(2)}$. Ginger, scientifically known as Zingiber Officinale Roscoe, is a plant rich in phytochemicals, administered as a medicinal

\footnotetext{
* Demonstrator at Oral and Maxillofacial Pathology, Faculty of Dentistry, Cairo University.

** Professor of Oral and Maxillofacial Pathology, Faculty of Dentistry, Cairo University.

*** Assistant Professor of Oral and Maxillofacial Pathology, Faculty of Dentistry, Cairo University
} 
remedy, as a nutritional supplement and as a flavoring agent ${ }^{(3)}$. The bioactive molecules gingerols and shogaols in Ginger are responsible for its antiinflammatory activities through prostaglandins and leukotriene biosynthesis inhibition ${ }^{(4)}$.

\section{MATERIAL AND METHODS}

\section{Experimental Animals}

Three to four months old male albino rats $(\mathrm{n}=16)$ with a mean weight of 150-200 gm, were purchased and housed in the animal house, Faculty of Medicine, Cairo University.

\section{II- Archival blocks}

Archival blocks for untreated control group and Cetuximab group were obtained.

\section{Inflammation induction and Ginger adminis- tration:}

Cetuximab drug was administered by intraperitoneal injection every 3 days for five total injections at a dose level of $0.25 \mathrm{mg} /$ injection. Aqueous Ginger infusion was given orally by gavage at a daily dose of $400 \mathrm{mg} / \mathrm{kg}$.

\section{Histopathological Examination}

The specimens of the dissected tongue of all groups were fixed immediately in $10 \%$ neutral buffered formalin for 24 hours. The specimens were longitudinally cut, dehydrated in ascending grades of ethyl alcohol, cleared in xylene and embedded in paraffin. Then sections of 5 micron thickness were cut from paraffin blocks and mounted on glass slides for Haematoxylin \& Eosin (H\&E) staining and subsequent examination under the ordinary light microscope.

\section{Immunohistochemistry}

Immunostaining for COX-2 was done for all using Ventana Benchmark autostainer and the following steps occurred automatically: deparraffinization, cell conditioning (standard conditioning for 80 minutes), application of COX-2 mouse monoclonal antibody
(2145 Delware Ave, Santa Cruz, CA 95060, USA), under incubation temperature at $37^{\circ} \mathrm{C}$ for 44 minutes, Application of DAB, Counter stain with Hematoxylin for 8 minutes and Post counter stain with bluing reagent for 4 minutes. The positive immunoreaction of COX-2 was detected by the color of the chromogen in a pale blue background and was assessed by two methods as follows:

\section{a) Ordinary light Microscope}

This method is used to assess the prevalence of immunopositivity of COX-2 in the studied sections.

\section{b) Evaluation of immunoexpression}

All the immunostained sections were examined by the image analyzer computer system using the software Leica Qwin 500 (Germany) in the Center of Research and Dental Requirements, Faculty of Dentistry, Cairo University. The image analyzer was calibrated automatically to convert the measurement units (pixels) into actual micrometer units. The area percent was measured, where five fields of each slide was measured using a magnification (x200).

\section{Statistical Analysis}

Values were presented as mean and standard deviation values. Data were explored for normality using Kolmogorov-Smirnov test of normality. The results of Kolmogorov- Smirnov test indicated that most of data were normally distributed (parametric data), therefore one way analysis of variance (ANOVA) test was used to compare between groups. This was followed by Duncan post hoc test for multiple pairwise comparisons. The significance level was set at $\mathrm{p} \leq 0.05$. Statistical analysis was performed with SPSS 16.0 (Statistical Package for Scientific Studies, SPSS, Inc., Chicago, IL, USA) for Windows.

\section{RESULTS}

In Cetuximab group, marked positive COX-2 immunoexpression was observed in the epithelium of the rat tongue mucosa. COX-2 immunoexpression was predominantly localized in the cytoplasm of the basal 
cells associated with obvious membranous expression in the prickle cell layer. Obvious cytoplasmic COX-2 immunoexpression was also noted in the stromal cells in the connective tissue (Figure 1).

In Cetuximab + Ginger group, faint COX-2 immunoexpression was observed in the epithelial layers and in sporadic stromal cells and some endothelial cells in the connective tissue (Figure 2) while in Ginger one week ahead of Cetuximab group, faint COX-2 immunoexpression was observed in the epithelial layers however, obvious cytoplasmic COX-2 immunoexpression was noted in stromal cells in-

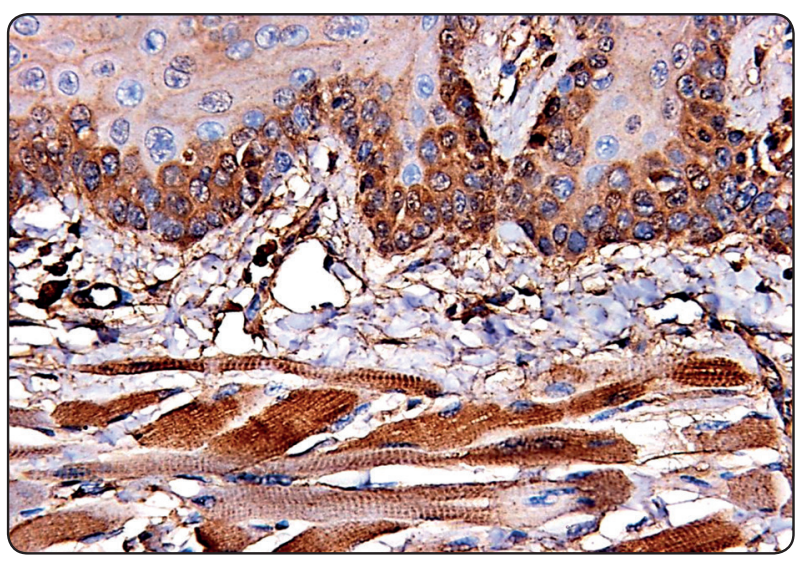

Fig. (1): A photomicrograph of Cetuximab group showing marked cytoplasmic COX-2 immunoexpression in the basal cells associated with obvious membranous expression in the prickle cell layer. Marked cytoplasmic COX-2 immunoexpression was also noted in the stromal cells in the connective tissue and in the striated muscles as well (Anti-COX-2 x400). cluding fibroblasts and inflammatory cells and also in some endothelial cells.

The greatest mean area percent $(12.3 \pm 0.78)$ was recorded in Cetuximab drug group, whereas the lowest value $(4.86 \pm 1.79)$ was recorded in Control group. One way analysis of variance (ANOVA) test revealed that the difference between all groups was statistically significant $(\mathrm{P}<0.001)$. Tukey's post hoc revealed no significant difference between Control, Ginger in parallel or one week ahead groups While Cetuximab drug group showed significant difference with all groups (Table 1).

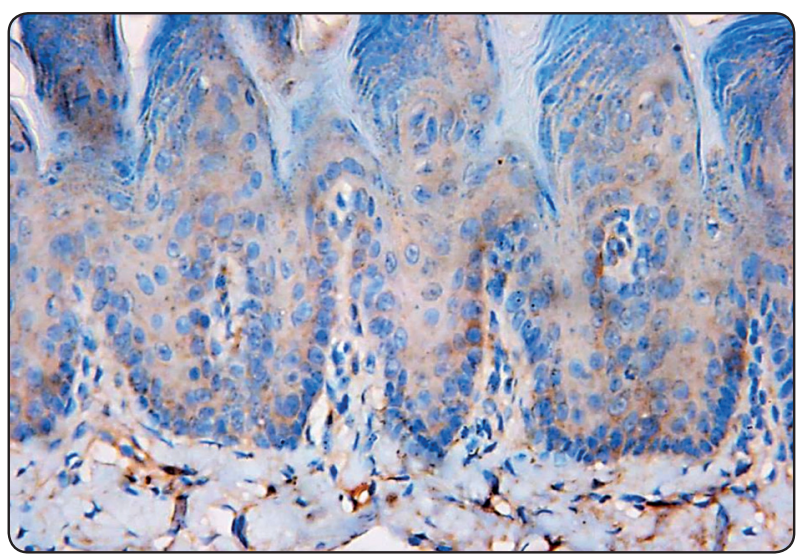

Fig. (2): A photomicrograph of Cetuximab plus Ginger group showing faint cytoplasmic COX-2 immunoexpression in the basal and prickle cell layers of the epithelium, sporadic stromal cells and some endothelial cells in the connective tissue (Anti-COX-2 x400).

TABLE (1): Area percent of COX-2 immunoexpression in all groups and significance of the difference using (ANOVA) test

\begin{tabular}{|l|c|c|c|c|}
\hline \multicolumn{1}{|c|}{ P.O.C } & $\begin{array}{c}\text { Control } \\
\text { Group }\end{array}$ & $\begin{array}{c}\text { Cetuximab } \\
\text { drug Group }\end{array}$ & $\begin{array}{c}\text { Ginger + Cetuximab } \\
\text { Group }\end{array}$ & $\begin{array}{c}\text { Ginger one week ahead of } \\
\text { Cetuximab Group }\end{array}$ \\
\hline Mean & $4.86^{\mathrm{a}}$ & $12.3^{\mathrm{b}}$ & $5.31^{\mathrm{a}}$ & $7.085^{\mathrm{a}}$ \\
\hline Std. Deviation & 1.79 & 0.78 & 0.95 & 1.835 \\
\hline Std. Error & 0.893 & 0.391 & 0.425 & 0.749 \\
\hline Max & 7.01 & 13.41 & 6.318 & 10.335 \\
\hline Min & 2.8 & 11.38 & 3.995 \\
\hline F value & \multicolumn{3}{|c|}{28.815} \\
\hline P Value & \multicolumn{3}{|c|}{$0.001^{*}$} \\
\hline
\end{tabular}

Significance level p<0.05, * significant Tukey's post hoc test: means sharing the same superscript letter are not significantly different. 


\section{DISCUSSION}

Cetuximab drug is an FDA approved drug in treatment of HNSCCs. Cetuximab has a 5 to 10 fold higher affinity than other EGFR ligands inhibiting dimerization and activation of the receptor resulting in a number of anti-tumour effects such as inhibition of cell growth and survival and inhibition of angiogenesis and metastasis ${ }^{(5)}$.

Ginger is well known for its remarkable nutraceutical value, which can be assigned to a variety of bioactive compounds including the gingerols and the shogaols attributing to endless pharmacological activities and physiologic effects (6). It exerts its anti-inflammatory effect through dual inhibition of cyclooxygenases (COX-1 and COX2) and 5-LOX thus suppressing PG and leukotriene synthesis providing a better therapeutic profile and fewer side effects ${ }^{(7)}$, which is mainly due to its action on NF- $\varkappa \mathrm{B}^{(8)}$.

In our study, examination of COX-2 immunostained sections showed cytoplasmic COX-2 immunoexpression in the basal and prickle cells of the epithelium in all groups. It was also expressed in the cytoplasm of the stromal and endothelial cells of the connective tissue in all groups.

COX-2 expression was more pronounced in the basal cells of the epithelium in the group taking Cetuximab alone in comparison with the other groups which could be explained by the role of EGFR in epithelial cell differentiation and development and its higher expression in the basal cells of the epidermis ${ }^{(9)}$. Therefore inhibition of EGFR by Cetuximab resulted in injury of the basal cells thus initiating the inflammatory response and COX-2 expression mainly in basal cells.

Statistical analysis of the current results regarding area percent values of COX-2 immunoexpression in the epithelium revealed a significant upregulation in the group taking Cetuximab drug alone revealing the effect of Cetuximab on eliciting an inflammatory response. This is in accordance with the study which revealed that Cetuximab causes oral mucositis which is less ulcerative but more widespread and accompanied by general erythema compared to conventional chemotherapy ${ }^{(\mathbf{1 0})}$.

Statistical analysis of the results of the current experiment revealed a significant decrease in mean area percent values for COX-2 immunoexpression in rats receiving Ginger either in parallel courses or one week ahead of Cetuximab compared to those receiving Cetuximab alone. This could be explained by the presence of some gingerol compounds including gingerols and shogaols inhibit the inducible form, COX-2 three-fold more than COX1 contributing to the anti-inflammatory property of Ginger ${ }^{(11)}$.

It is apparent that Ginger as a herbal drug, is one of the potent nutraceutical agents with remarkable anti-inflammatory benefits and a great acceptance in the population.

\section{REFERENCES}

1- Vigarios, E., Epstein, J. B., \& Sibaud, V. (2017). Oral mucosal changes induced by anticancer targeted therapies and immune checkpoint inhibitors. Supportive Care in Cancer, 25(5), 1713-1739.

2- Yarom, N., Ariyawardana, A., Hovan, A., Barasch, A., Jarvis, V., Jensen, S. B., et al., (2013). Systematic review of natural agents for the management of oral mucositis in cancer patients. Supportive Care in Cancer, 21(11), 32093221 .

3- Inserra, P., \& Brooks, A. (2017). Nutritional Modulators of Pain in the Aging Population, USA, Academic Press, pp. 67-73.

4- Mashhadi, N. S., Ghiasvand, R., Askari, G., Hariri, M., Darvishi, L., \& Mofid, M. R. (2013). Anti-oxidative and anti-inflammatory effects of ginger in health and physical activity: review of current evidence. International Journal of Preventive Medicine, 4(1), S36-42.

5- Frampton, J. E. (2010). Cetuximab. Drugs, 70(15), 19872010 . 
6- Sharifi-Rad, M., Varoni, E., Salehi, B., Sharifi-Rad, J., Matthews, K., Ayatollahi, S., et al., (2017). Plants of the genus Zingiber as a source of bioactive phytochemicals: From tradition to pharmacy. Molecules, 22(12),2145-2164.

7- Kumar, S., Saxena, K., Singh, U. N., \& Saxena, R. (2013). Antiinflammatory action of ginger: A critical review in anemia of inflammation and its future aspects. International Journal of Herbal Medicine, 1, 16-20.

8- Sharma, V., Sinh, A., \& Thakur, V. (2015). Ginger: pharmacotherapeutic significance as an anti-inflammatory drug. European Journal of Molecular Biology and Biochemistry, 2(4), 153-159.

9- Xu, M. J., Johnson, D. E., \& Grandis, J. R. (2017). EGFRtargeted therapies in the post-genomic era. Cancer and Metastasis Reviews, 36(3), 463-473.

10- Musio, D., De Felice, F., Bulzonetti, N., \& Tombolini, V. (2013). Cetuximab and oral mucositis: is it different from oral mucositis caused by other drugs. Otolaryngology, 3(4), 1-4.

11- Van Breemen, R. B., Tao, Y., \& Li, W. (2011). Cyclooxygenase-2 inhibitors in ginger (Zingiber officinale). Fitoterapia, 82(1), 38-43. 